\title{
Neuro-fuzzy Controller for High Performance Induction Motor Drives
}

\author{
K. Mohanasundaram \\ Research Scholar \\ Anna University of Technology \\ Coimbatore
}

\author{
Dr. K. Sathiyasekar \\ Principal \\ CMS College of Engineering \\ Namakkal
}

\author{
Dr. N. Rajasekar \\ Professor/EEE \\ VIT University \\ Vellore
}

\begin{abstract}
This paper presents development of a neuro-fuzzy system for performance enhancement of a.c.voltage controller fed induction motor drives. Improvement in motor efficiency and power factor is achieved by suitably adapting the motor flux to optimum point by stator voltage control. The optimum SCR firing angle for each operating point is readily estimated by the neuro-fuzzy system. Extensive simulation is carried out with the proposed technique and the results are presented.
\end{abstract}

\section{Keywords}

Induction motor, a.c. voltage controller, Modeling, Fuzzy logic.

\section{INTRODUCTION}

Induction motors are driving force of any industry and it is estimated that such drives consume about $60 \%$ of total electrical energy generated in developing/developed countries. Hence, improvement in the energy efficient operation of induction motors will result in enhanced energy saving. Generally motors run on full load only part of its duty cycle and since its efficiency is maximum only at full load, the average motor efficiency is inferior. This is compounded by the fact that many times over rated motors are employed in industries expecting future expansion. Thus considerable period of motor duty cycle contains light load conditions leading to poor operating efficiency. During part-load conditions, efficiency enhancement can be achieved by suitably adjusting the motor flux to cope with load torque demand. With reduced air-gap flux, iron losses and magnetizing current are reduced leading to improved motor efficiency and power factor [1-5]. There are two basic approaches to achieve this goal. One possibility is to use a variable frequency drive (VFD) to adjust motor terminal voltage and frequency to reach the optimum flux. The second method is to use soft starter for adjusting motor terminal voltage alone; frequency is unchanged. VFD is more expensive and is not a preferred option with certain loads such as fan and pump drives and such applications can be equipped with low cost soft starter. Hence the motor voltage can be controlled during lightly loaded conditions using ac voltage controller to achieve best efficiency and power factor. The concept of performance enhancement of lightly loaded induction motor was well perceived in the literature and several papers have been published in this topic. However, the major drawback of all these works is that optimum efficiency point is generally attained using a search algorithm, in which stator voltage reduction is carried out by trial and error based approach. The search algorithm takes more time for reaching the optimum point than reasonable be allowed. The step wise change in SCR firing angle results in poor dynamic response of the drive performance. Further/more optimum efficiency point is never reach and persistent oscillations about this point are observed which requires an additional controller [6].

The aim of the present paper is to explore soft computing methodologies, namely fuzzy logic and neural networks [7-10] to provide a reliable and fast acting control system for performance enhancement of voltage controlled induction motor drive. For this, the $\mathrm{d}-\mathrm{q}$ axis model of induction motor model is simulated for a wide range of operating point, keeping SCR firing angle and load torque as independent variables. From the simulation results, fuzzy logic system is developed for identifying the optimum SCR firing angle during a load change. In order to gain the advantages of fuzzy logic and neural networks, a neuro-fuzzy system is then constructed $[11,12,13,14]$ and is used in conjunction with induction motor model. The complete drive system together with neuro-fuzzy estimator is developed Matlab/Simulink [15, 16]. Simulation results are presented and these results validate the proposed method.

\section{DEVELOPMENT OF FUZZYLOGIC ESTIMATOR}

The schematic of a.c.voltage controller fed induction motor drive is shown in figure 1.

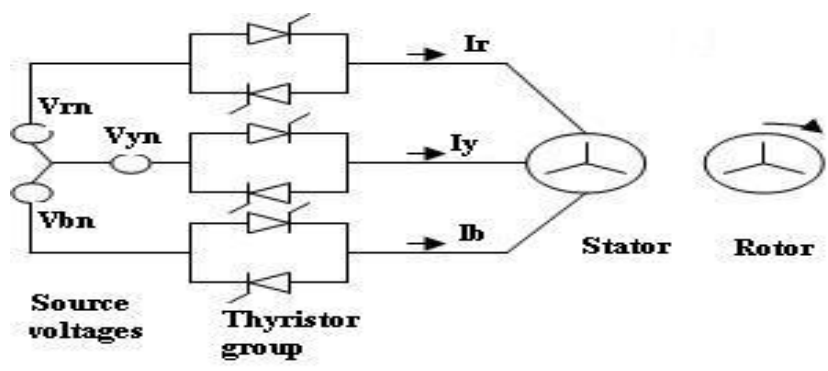

Figure1.Induction motor drive with SCR Voltage Controller

The task here is to identify suitable SCR firing angle for maximum efficiency, when load change occurs. In order to obtain information base for developing input and output fuzzy sets, dynamic simulation of ac voltage controller fed induction motor drive is carried out for wide range of operating points. The motor vector matrix differential equation in stator $\mathrm{d}-\mathrm{q}$ axis frame is given by $[17,18]$ 
$\left[\begin{array}{c}\frac{d i_{d s}}{d t} \\ \frac{d i_{q s}}{d t} \\ \frac{d i_{d r}}{d t} \\ \frac{d i_{q r}}{d t}\end{array}\right]=\frac{1}{\sigma}\left[\begin{array}{cccc}\frac{-r_{s}}{L_{s}} & \frac{\omega_{r} L_{m}^{2}}{L_{s} L_{s}} & \frac{r_{s} L_{m}}{L_{s} L_{r}} & \frac{\omega_{r} L_{m}}{L_{s}} \\ \frac{\omega_{r} L_{m}^{2}}{L_{s} L_{s}} & \frac{-r}{L_{s}} & \frac{\omega_{r} L_{m}}{L_{s}} & \frac{r_{r} L_{m}}{L_{s} L_{r}} \\ \frac{r_{s} L_{m}}{L_{s} L_{r}} & \frac{\omega_{r} L_{m}}{L_{s}} & \frac{r_{r}}{L_{r}} & \frac{\omega_{r} L_{m}}{L_{s}} \\ \frac{\omega_{r} L_{m}}{L_{s}} & \frac{r_{s} L_{m}}{L_{s} L_{r}} & \frac{\omega_{r} L_{m}}{L_{s}} & \frac{r_{r}}{L_{r}}\end{array}\right]\left[\begin{array}{l}i_{d s} \\ i_{q s} \\ i_{d r} \\ i_{q r}\end{array}\right]+\frac{1}{\sigma}\left[\begin{array}{cccc}\frac{1}{L_{s}} & 0 & 0 & 0 \\ 0 & \frac{1}{L_{s}} & 0 & 0 \\ 0 & 0 & \frac{1}{L_{r}} & 0 \\ 0 & 0 & 0 & \frac{1}{L_{r}}\end{array}\right]\left[\begin{array}{l}V_{d s} \\ V_{q s} \\ 0 \\ 0\end{array}\right]$

where $\sigma=\frac{L_{m}^{2}}{L_{s} L_{m}}, \quad V_{d s}$ and $V_{q s}$ are functions of $\alpha$.

The electromagnetic torque is governed by the equation,

$T_{e}=\sqrt{\frac{3}{2}} \frac{P_{0}}{2} L_{r}\left(i_{d r} i_{q s}-i_{q r} i_{d s}\right)$

Now, equating the electrical torque developed by the motor with the mechanical torque required to drive the rotor and load, the following equation is obtained.

$J \frac{d\left(\Delta \omega_{r)}\right.}{d t}+F \Delta \omega_{r}=\Delta T_{e}-\Delta T_{L}$

The induction motor model with ac voltage controller is developed in Matlab/Simulink. In this model, the independent variables are SCR firing angle $\alpha$ and load torque $T_{L}$. The power converter fed motor model is made to operate at a particular operating point with maximum efficiency by trial and error initially. The motor current at the optimum efficiency, $I_{o p t}$ at this point is noted. Load torque disturbance is now applied to this model and the new motor current, correspond to this operating point is noted as $I_{n e w}$. The SCR firing angle is now gradually changed so as to reach minimum motor current which corresponding to the maximum efficiency point. Once this point is reached, the SCR firing angle, $\alpha_{o p t}$, is measured. The idea is to develop a non-linear relational mapping between $I_{\text {opt }}, I_{\text {new }}$ and $\alpha_{\text {opt }}$. It is proposed to write this relationship as

$$
\alpha_{o p t}=f\left(I_{o p t,} I_{n e w}\right)
$$

Elaborate simulations are carried out so as to cover the entire operating range of the motor and each time the above three variables were recorded. After sufficient data is obtained for each of the above variable, fuzzy sets describing the above variables are constructed. This was done through a trial and error based approach. The fuzzy sets thus designed as shown in figure 2 .
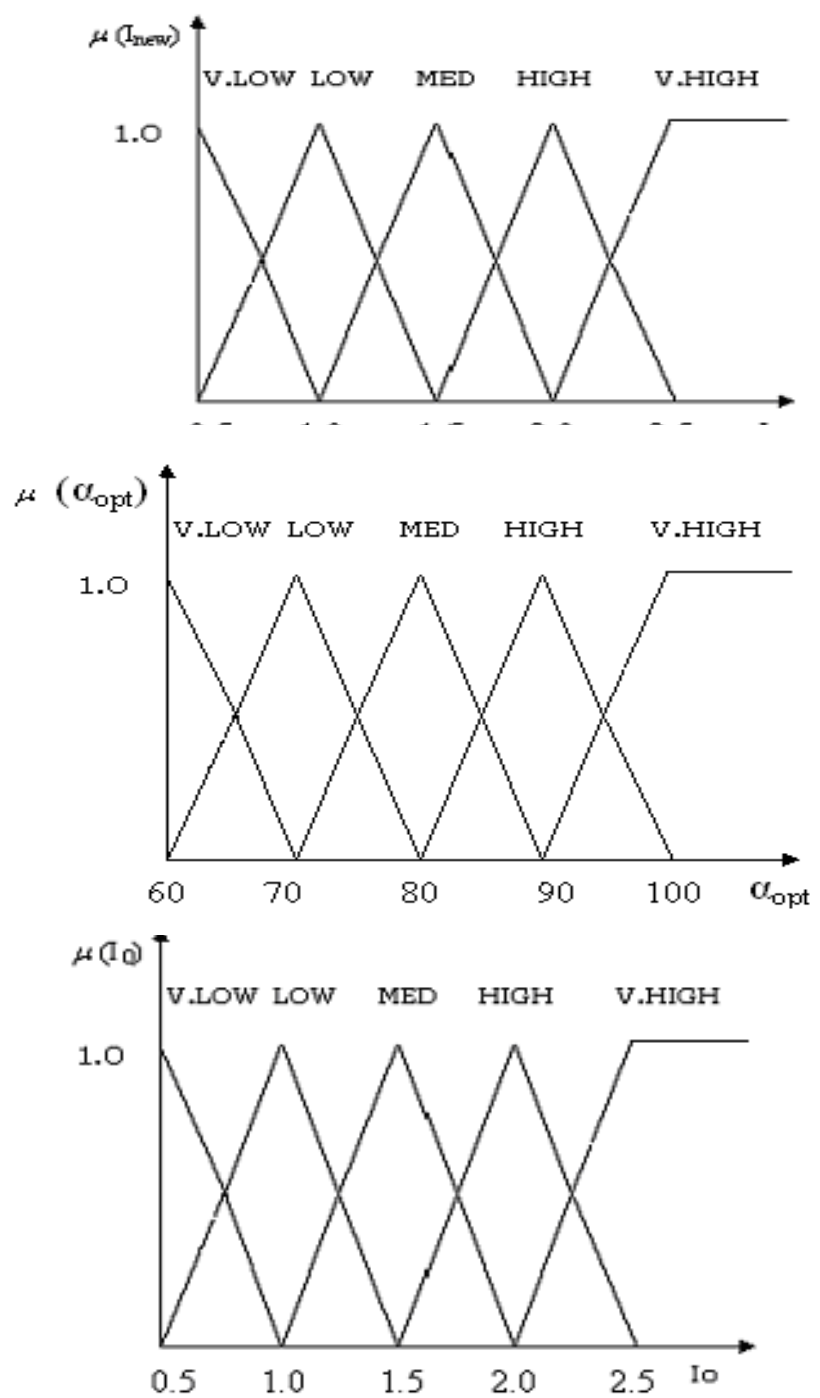

Figure 2. Fuzzy sets for (a) $I_{\text {opt }}$ (b) $I_{\text {new }}$ and ( c) $\alpha_{\text {opt. }}$

After constructing the fuzzy sets, a rule base is developed based on the simulation results. The fuzzy associative memory (FAM) thus generated is shown in figure3.

\begin{tabular}{|c|c|c|c|c|c|}
\hline $\mathrm{I}_{\text {new }} \mathrm{I}_{\text {opt }}$ & V.LOW & LOW & MED & HIGH & V.HIGH \\
\hline V.LOW & V.HIGH & MED & MED & LOW & V.LOW \\
\hline LOW & - & V.LOW & V.HIGH & LOW & \\
\hline MED & V.HIGH & V.HIGH & V.HIGH & V.HIGH & V.LOW \\
\hline HIGH & - & V.HIGH & HIGH & HIGH & - \\
\hline V.HIGH & HIGH & HIGH & MED & MED & V.LOW \\
\hline
\end{tabular}

Figure 3. Rule base of fuzzy estimator for the ac voltage controller fed induction motor drive 


\section{DEVELOPMENT OF NEURO-FUZZY SYSTEM}

In order to gain both the advantages of fuzzy systems and neural networks-fuzzy logic allows a reasonable amount of approximations and uncertainties, while neural network is computationally compact and fast-a neuro-fuzzy system is now developed. In the present case there are two inputs namely, $I_{\text {opt }}, I_{n e w}$ and a single output, $\alpha_{\text {opt }}$. Hence there should be two input neurons and a single output neuron. No attempt has been made to optimize the number of hidden neurons and is obtained by trial and error. It is found that five neurons are sufficient for mapping the input-output relationship obtained through fuzzy logic system. The fuzzy logic estimator developed earlier, is fed with numerous inputs and outputs are obtained. This information base thus obtained is used to train the neural network. The training of the network is carried out using the neural network toolbox in Matlab. The structure of designed neural network is shown in figure 4 . The input and output neurons employ linear activation function, while the output neurons make use of typical sigmoid transfer functions. The weights and biases are included in figure 4 .

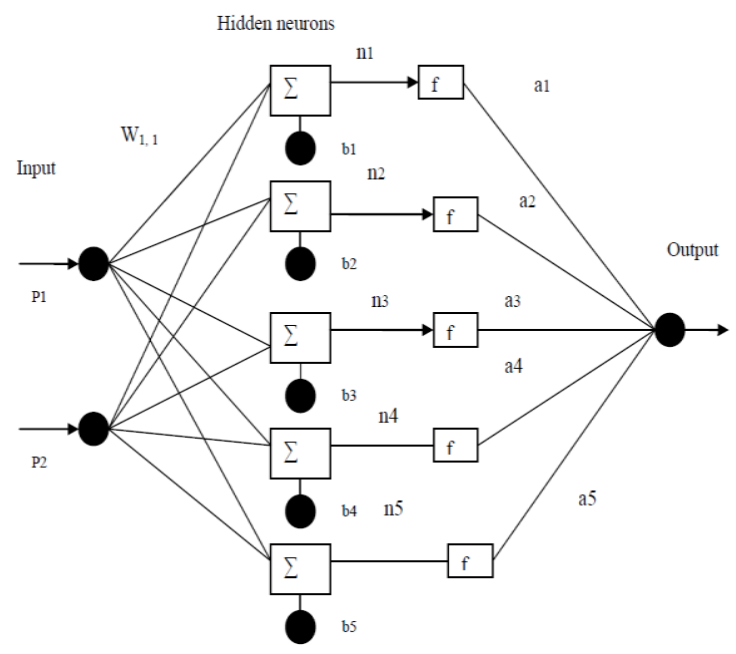

Figure 4. Topology of 2-5-1 feed forward neural network

\section{SIMULATION RESULTS}

In order to verify the proposed approach, the neural network is now integrated with ac voltage controlled fed drive model and the complete system is shown in figure 5. The simulation results are shown in figures 6 .

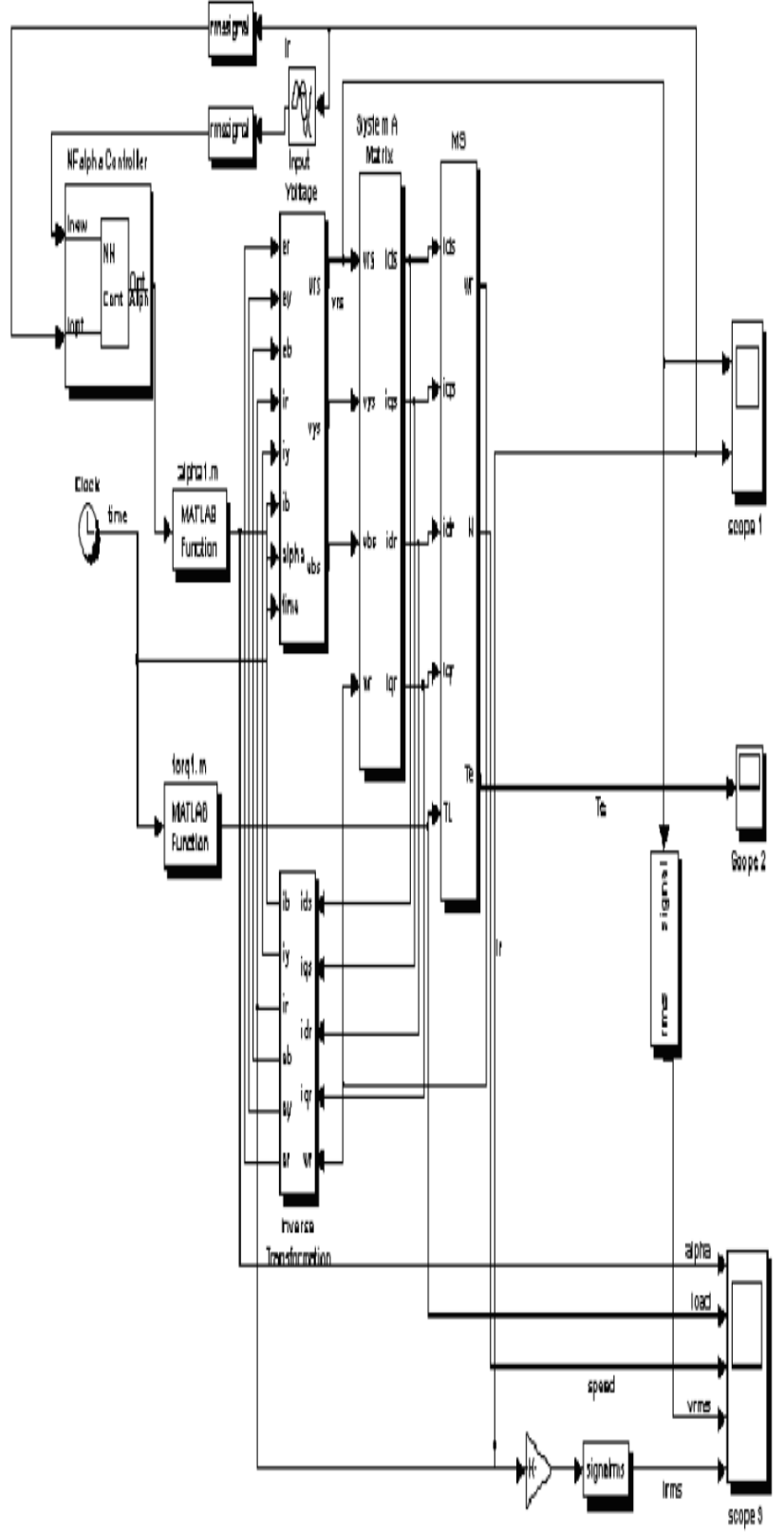

Figure 5.Matlab Model of Induction motor drive with neurofuzzy estimator 


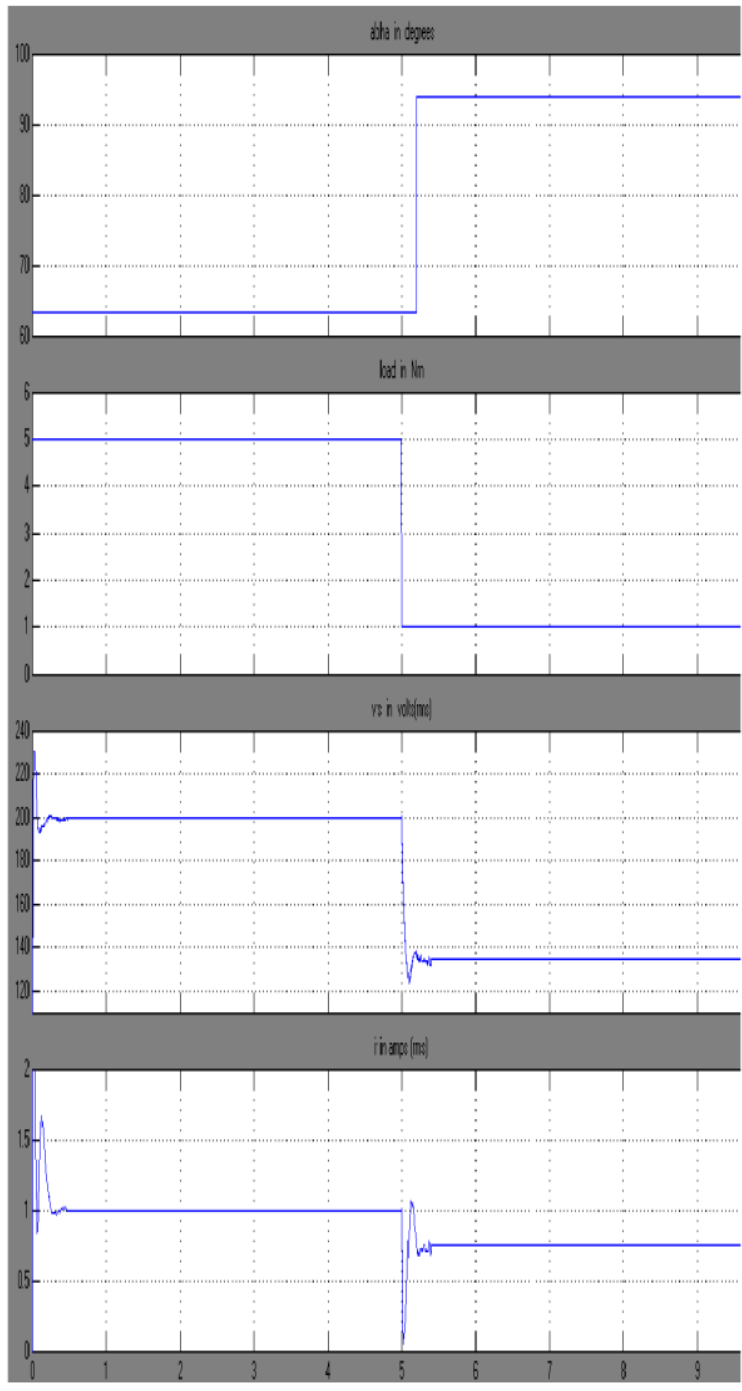

Figure 6.Dynamic response of drive with neuro-fuzzy estimator

In figure 6 , at $\mathrm{t}=0$, the motor is driving a load torque of $5 \mathrm{Nm}$ with an optimum SCR firing angle of 63.2 degrees. The rms value of optimum current, $I_{o p t}=1.3$ amperes. At $\mathrm{t}=5$ seconds, the load torque is decreased to $1.0 \mathrm{Nm}$. As can be seen, the new value of the motor current reduces to 0.8 amperes. The neural network estimates the value of the optimum SCR firing angle to be 93.9 degrees and the ac voltage controller is now fired at this optimum angle. The optimum value of voltage and current waveforms before and after load change are shown in figure 7 and figure 8 respectively.

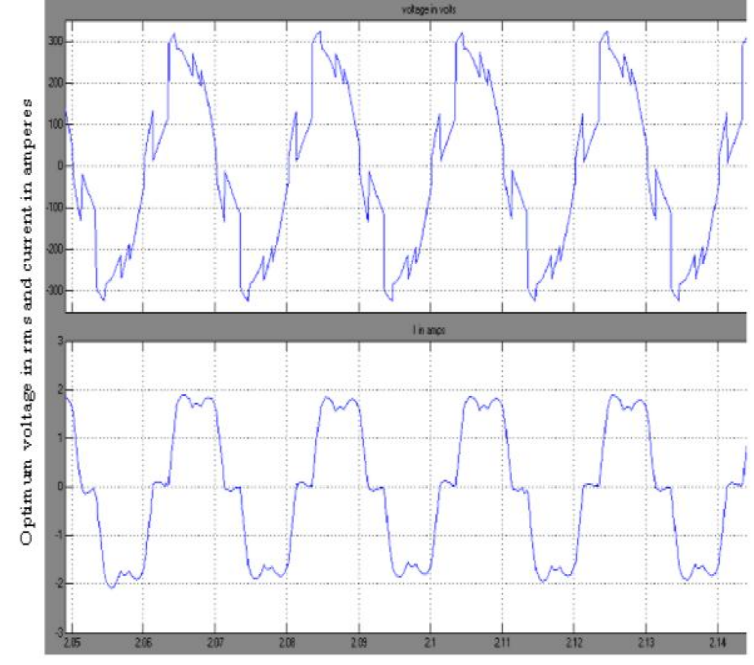

Time in seconds

Figure 7 . Voltage and current waveforms prior to load change (prior to optimization).

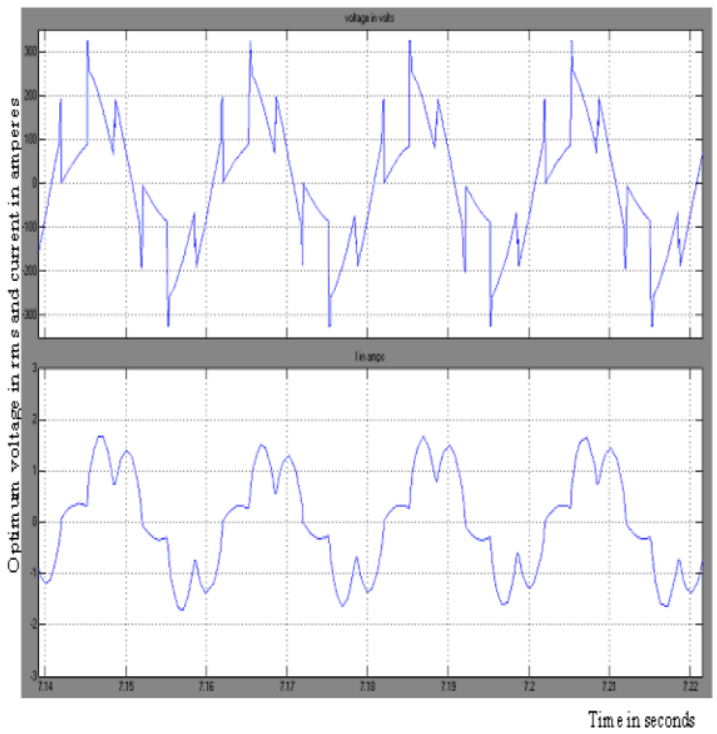

Figure 8. Voltage and current waveforms after optimization.

\section{CONCLUSION}

A fuzzy logic based optimum SCR firing angle identification is developed for efficiency maximization of variable-voltage partly loaded induction motor drive. The rule base is derived from extended simulation. In order to benefit the dual advantages of neural networks and fuzzy systems, a neural network is then developed. Simulation results are presented to validate proposed approach. 


\section{REFERENCES}

[1] N.Mohan, "Improvement in energy efficiency of induction motor by means of voltage control," IEEE Trans.on Power Apparatus and Systems, Vol.PAS-99, No.4, pp.1466-1470, July/Aug.1980.

[2] T.W.Roman and T.A.Lipo, "A quantitative analysis of induction performance improvement by SCR voltage control," IEEE Trans.on Power Apparatus and Systems, Vol.PAS-19, No.4, pp.545-553, July/Aug.1983.

[3] V.V.Sastry, M.R.Prasad, and T.V.Sivakumar, "Optimal soft starting of voltage controlled fed IM drive based on voltage across thyristor," IEEE Trans.on Power Electronics, Vol 12, No.6, pp.1041-1051, November 1997.

[4] P.Famouri and J.J.Cathey, "Loss minimization control of an induction motor drive," IEEE Trans. on Industry Applications, Vol.27, No.1, pp.32-37, Jan/Feb.1991.

[5] I.Kioskerdis and N.Margaris, "Loss minimization in scalar-controlled Induction motor drives with search controllers," IEEE Trans. on Power Electronics, Vol.11, No.2, pp.213-220, March 1996.

[6] B.K.Bose, N.R.Patel and K.Rajashekaran, "A neurofuzzy on line efficiency optimization control of a stator flux-oriented direct vector controlled induction motor drive," IEEE Trans. on Industrial Electronics, Vol.44, No.2, pp.270-273, April 1997.

[7] M.L. Benloucif, and L. Mehenaoui, "A fuzzy neural scheme for fault diagnosis," Proc. International Computer Systems and Information Technology Conference ICSIT'05, Algiers, July 19-21, 2005

[8] M. Zerikat, M. Bendjebbar and N. Benouzza." Dynamic Fuzzy-Neural Network Controller for Induction Motor Drive" World Academy of Science, Engineering and Technology 2005

[9] Hassan Baghgar Bostan Abad, Ali Yazdian Varjani, Taheri Asghar, "Using Fuzzy Controller in
InductionMotor Speed Control withConstant Flux", Proc. of world academy of science, engineering and technology, Vol.5,ISSN 1307-6884, April 2005

[10] M. N. Uddin and Hao Wen, "A Neuro- fuzzy Base Hybrid Intelligent Controller for High Performance Induction Motor Drives", IEEE IAS Conf. Record, Seattle, USA, 2004, pp. 2630-2636.

[11] M.T.Hogon and H.B.Demuth, Neural network design, PWS publishing company, Boston, 1996.

[12] Ashok Kusagur, S.F. Kodad, B.V. Sankar Ram, "Modelling of Induction Motor \& Control of Speed Using Hybrid Controller Technology", Proc. Int. Journal of Theoretical Information \& Technology (JATIT), Vol. 10,issue 2, pp. 117-126, Dec. 2009

[13] Ashok Kusagur, Dr. S. F. Kodad, Dr. B V. Sankar Ram Modeling, Design \& Simulation of an Adaptive Neuro- Fuzzy Inference System (ANFIS) for Speed Control of Induction Motor ,International Journal of Computer Applications (0975 - 8887)Volume 6- No.12, September 2010.

[14] Zulkarnain Lubis, Solly aryza, Ahmed N Abdalla, Zulkeflee Bin Khalidin "A Novel Induction Motor Speed Estimation Using Neuro - Fuzzy ", International Conference on Circuits, System and Simulation, vol.7 2011.

[15] MATLAB, High performance numeric computation and visualization software, Reference Guide, Mathworks Inc., 1992.

[16] SIMULINK, Dynamic system simulation for MATLAB Version 2 Mathworks Inc., January 1997.

[17] P.C.Krause, Analysis of electric machinery, Mc.GrawHill, 1986.

[18] B.K.Bose, Power electronics and AC Drives, Engelwood cliffs NJ, PrenticeHall, 1986. 